\title{
On the Prediction of Hot Tearing in Al-to-Steel Welding by Friction Melt Bonding
}

\author{
N. JIMENEZ-MENA, P.J. JACQUES, J.M. DREZET, and A. SIMAR
}

\begin{abstract}
Aluminum alloy AA6061 was welded to dual-phase steel 980 (DP980) by the friction melt bonding (FMB) process. Hot tears have been suppressed by controlling the thermomechanical cycle. In particular, the welding speed and the thermal conductivity of the backing plate have been optimized. A finite-element thermomechanical model coupled with the RappazDrezet-Gremaud (RDG) criterion has been used to explain these experimental observations. The hot tear susceptibility has been reduced with large thermal gradients and with the formation of a cellular microstructure. Both effects are favored by a backing plate made of a material with high thermal conductivity, such as copper.
\end{abstract}

https://doi.org/10.1007/s11661-018-4618-z

(C) The Minerals, Metals \& Materials Society and ASM International 2018

\section{INTRODUCTION}

THE tight regulations regarding the greenhouse gas emissions generated by the transportation convinced the industry to reduce the weight of vehicles' structures. An efficient combination of the properties of aluminum and advanced high-strength steels (AHSS) is regarded as a promising solution to reduce the weight of cars. ${ }^{[1]}$

However, the dissimilar welding of aluminum and steel is challenging due to the metallurgical incompatibility of the two materials. ${ }^{[2]}$ At first, the challenges are to treat the large differences in melting temperatures and thermal expansion coefficients of both materials. In addition, the formation of a reacting brittle intermetallic layer (IML) results in poor mechanical properties of the assembly. ${ }^{[3,4]}$ Most of the joining techniques lead to the formation of this brittle intermetallic layer (IML). This is the case for most welding techniques such as friction stir welding, ${ }^{[4-6]}$ friction welding ${ }^{[7]}$ laser welding, ${ }^{[8]}$ and arc welding. ${ }^{[2]}$ According to Tanaka et al. ${ }^{[4]}$ the thickness of the IML determines the toughness of the joint. There is a significant increase in fracture toughness for IML thicknesses below $1 \mu \mathrm{m}$.

Friction melt bonding (FMB) has recently been developed to join sheets of dissimilar materials in a lap-joint configuration. ${ }^{[9,10]}$ This process is adapted to weld materials showing large differences in melting temperature (i.e., aluminum and steel). In this process,

N. JIMENEZ-MENA, P.J. JACQUES, and A. SIMAR are with the iMMC-IMAP, Université catholique de Louvain, 1348, Louvainla-Neuve, Belgium. Contact e-mail: aude.simar@uclouvain.be J.M. DREZET is with the École polytechnique fédérale de Lausanne, IMX, 1015, Lausanne, Switzerland.

Manuscript submitted July 19, 2017.

Article published online April 13, 2018 sketched in Figure 1(a), the steel plate is heated up by a rotating cylindrical tool pressed against its upper surface. The generated heat is not large enough to melt steel, but it locally melts the aluminum in contact with its bottom surface. The tight contact between the molten aluminum and the steel surface leads to some reactivity and the formation of the IML. No protective atmosphere is needed since the molten Al is confined within the assembly and is not in contact with the atmosphere.

In previous studies, van der Rest et al. ${ }^{[9]}$ and Crucifix et al. ${ }^{[1]}$ observed hot tears in the re-solidified aluminum after FMB. Such hot tears were located in the molten pool close to the aluminum-steel interface. This location corresponds to the last re-solidified aluminum. van der Rest et al. ${ }^{[9]}$ highlighted the influence of the aluminum composition on the formation of hot tears when welded to ultra-low-carbon (ULC) steel. They observed that the commercially pure aluminum alloy AA1050 was free of hot tears, while age-hardenable AA2024 led to hot tearing. Crucifix et al. ${ }^{[11]}$ considered the thermal cycles when welding AA2024 to ULC steel. They observed that the number of hot tears increased as the welding speed increased. They suggested that the size of the molten pool might be used as a criterion to predict the formation of hot tears. They concluded that a larger molten pool may reduce the hot tear formation.

The Rappaz-Drezet-Gremaud (RDG) criterion ${ }^{[12]}$ provides a physically based explanation of the hot tearing phenomenon. It states that hot tears nucleate in the intergranular liquid during solidification. This occurs in a cavitation-like process if a critical drop of pressure is reached. They identified both the permeability of the "solid plus liquid" mixture and the thermomechanical cycle during solidification to be responsible for this drop of pressure. With this as criterion, it is possible to assess the influence of alloy composition and 


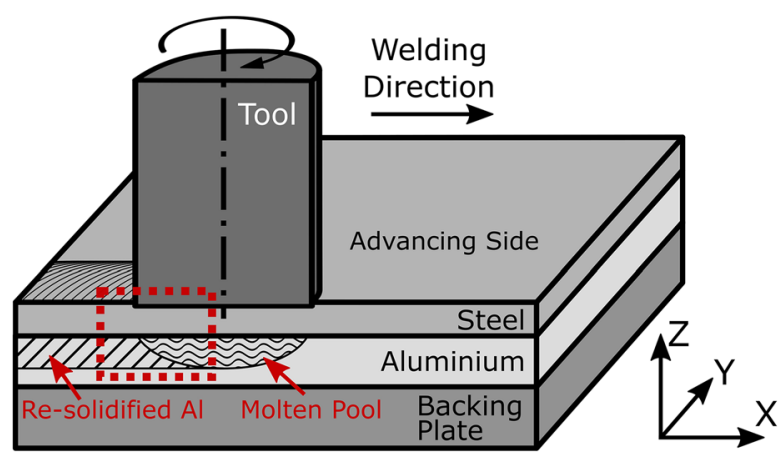

(a)

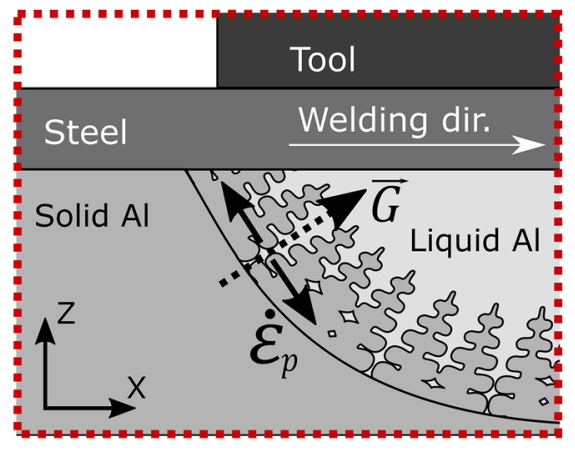

(b)

Fig. 1-(a) Schematic representation of the FMB process. (b) General description of the solidifying region of the molten pool delimited by the dashed square in (a). The dendritic grains grow in the direction of $\vec{G}$. The mechanical strain rate that pulls apart the grains $\left(\dot{\varepsilon}_{\mathrm{p}}\right)$ acts in a direction perpendicular to $\vec{G}$.

thermomechanical parameters on the propensity of hot tear formation. ${ }^{[13]}$ In the previously discussed welds performed by Crucifix et al., ${ }^{[1]]}$ the hot tearing susceptible alloy AA2024 was welded to steel. The combination of large cooling rates - and by extension large strain rates - seemed to be responsible for the formation of hot tears, rather than the size of the molten pool.

Some authors already approached the hot tearing phenomenon using finite-element (FE) modeling to simulate the influence of the thermomechanical cycles. Drezet et $a l .{ }^{[13]}$ performed thermal simulations of an AA6056 laser weld. They coupled these simulations with the RDG criterion to compute the maximum strain rate allowable in the mushy zone. They could thus identify a hot tearing susceptibility (HTS) parameter as the inverse of the maximum allowable strain rate, $1 / \dot{\varepsilon}_{\text {p, max }}$. In addition, using coupled thermomechanical simulations, they assessed the strain rates withstood by the mushy zone. They observed that hot tears were most likely to develop during the run-in and run-out stages of the laser pass.

Tian et al ${ }^{[14]}$ assessed the same HTS parameter as Drezet et al. ${ }^{[13]}$ for the laser welding of an AA2198 alloy. They calculated the maximum allowable strain in the mushy zone according to the composition and thermal fields during a laser pass.

Bakir et al. ${ }^{[15]}$ performed $\mathrm{FE}$ thermomechanical simulations of laser welding in stainless steel. The use of contact elements with a cohesive zone behavior allowed them to predict the crack length. In their work, the criterion for crack propagation was the maximum tensile stress in the brittle temperature range (BTR).

FMB presents two specific features that need to be accounted for during FE simulations. First, the molten pool is confined between the steel and the solid aluminum under the pressure of the tool. This may lead to a rise of pressure because of the constrained expansion of the liquid aluminum. Second, the surfaces of the steel and the aluminum are bonded together after the formation of the IML. This bonding leads to a load transfer between aluminum and steel. It thus contributes to the straining of the mushy zone.
The current study critically assesses the formation of hot tears resulting from FMB. Hot tears have successfully been suppressed by controlling the thermal cycle. Different thermal conditions were tested and modeled using FE simulations. The thermomechanical and metallurgical parameters identified in the section on RDG criterion were evaluated. Finally, the drop of pressure at the root of the dendrites was successfully used as a criterion to predict the formation of hot tears.

\section{RDG CRITERION}

The RDG criterion states that hot tears nucleate in the liquid between two grains through a cavitation-like process. ${ }^{[12]}$ If the pressure in the intergranular liquid reaches a critical pressure drop $(\Delta p$, units provided in Table I), a hot tear nucleates. This drop of pressure in the liquid between the grains has two origins: (i) the thermally induced deformation of the solid skeleton because of the cooling, and (ii) the shrinkage from the density differences between the liquid and solid phases during solidification. The pressure in the intergranular liquid increases with the solid fraction. According to the work of Sweet et al. ${ }^{[16]}$ the risk of hot tearing formation appears at solid fractions between the coherency fraction, $f_{\mathrm{o}}$, and the coalescence fraction, $f_{\text {co }}$. At coherency, corresponding to a temperature $\theta_{\mathrm{o}}$, the grains impinge. ${ }^{[17]}$ At coalescence, corresponding to a temperature $\theta_{\mathrm{co}}$, the grains bridge. The continuous liquid film between the grains is thus transformed into isolated liquid pockets, and the mushy zone starts to transmit strains and stresses as a solid. A representation of the directional grain growth in FMB is shown in Figure 1(b). The columnar grains grow in the molten pool parallel to the maximum temperature gradient, $\vec{G}$. Rappaz et al. ${ }^{[12]}$ identified the composition of the alloy and the thermomechanical cycle during solidification as the main parameters determining $\Delta p$. Imposing the mass conservation condition in a representative volume element, Rappaz et al..$^{[12]}$ showed that 
Table I. Table of Symbols

\begin{tabular}{|c|c|c|}
\hline Symbol & Description & Units \\
\hline$\alpha$ & coefficient of thermal expansion & $\mathrm{K}^{-1}$ \\
\hline$\beta$ & shrinkage factor & - \\
\hline$\dot{\varepsilon}_{\mathrm{p}}$ & mechanical strain rate & $\mathrm{s}^{-1}$ \\
\hline$\eta$ & efficiency of the heat input & - \\
\hline$\theta$ & temperature & $\mathrm{K}$ \\
\hline$\dot{\theta}$ & cooling rate & $\mathrm{K} \mathrm{s}^{-1}$ \\
\hline$k$ & thermal conductivity & $\mathrm{W} \mathrm{m}^{-1} \mathrm{~K}^{-1}$ \\
\hline$\lambda_{1}, \lambda_{2}$ & primary and secondary arm spacing & $\mathrm{m}$ \\
\hline$\mu$ & viscosity of the liquid between the grains & $\mathrm{Pa} \mathrm{S}$ \\
\hline$\omega$ & rotational speed of the tool & $\operatorname{Rad~s}^{-1}$ \\
\hline$f_{\underline{\mathrm{s}}}$ & solid fraction & - \\
\hline$\vec{G}$ & temperature gradient & $\mathrm{K} \mathrm{m}^{-1}$ \\
\hline$\Delta p$ & pressure drop & $\mathrm{Pa}$ \\
\hline$P$ & power input & $\mathrm{W}$ \\
\hline$\dot{Q}_{\text {surf }}$ & heat generated by friction at the steel surface & $\mathrm{W} \mathrm{m}^{-2}$ \\
\hline$\dot{Q}_{\mathrm{vol}}$ & heat generated by plastic deformation in the steel & $\mathrm{W} \mathrm{m} \mathrm{m}^{-3}$ \\
\hline$T_{\mathrm{z}}$ & torque at the tool & $\mathrm{N} \mathrm{m}$ \\
\hline$\vec{v}$ & speed of the solidification front & $\mathrm{m} \mathrm{s}^{-1}$ \\
\hline
\end{tabular}

$$
\Delta p=A \cdot \frac{1}{\lambda_{2}^{2}} \cdot \frac{\dot{\varepsilon}_{\mathrm{p}}}{|\vec{G}|^{2}}+B \cdot \frac{1}{\lambda_{2}^{2}} \cdot \frac{\dot{\theta}}{|\vec{G}|^{2}}
$$

where

$$
\begin{gathered}
A=180 \cdot(1+\beta) \cdot \mu \cdot \int_{\theta_{\mathrm{co}}}^{\theta_{\mathrm{liq}}} \frac{f_{\mathrm{s}}(\theta)^{2} \cdot \int_{\theta_{\mathrm{co}}}^{\theta} f_{\mathrm{s}}(\theta) \cdot \mathrm{d} \theta}{\left(1-f_{\mathrm{s}}(\theta)\right)^{3}} \cdot \mathrm{d} \theta, \\
B=180 \cdot \beta \cdot \mu \cdot \int_{\theta_{\mathrm{co}}}^{\theta_{\mathrm{liq}}} \frac{f_{\mathrm{s}}(\theta)^{2}}{\left(1-f_{\mathrm{s}}(\theta)\right)^{2}} \cdot \mathrm{d} \theta
\end{gathered}
$$

The relevant thermomechanical parameters are the mechanical strain rate perpendicular to the growth direction, $\dot{\varepsilon}_{\text {p }}$; the thermal gradient, $\vec{G}$; and the cooling rate, $\dot{\theta}$. The relevant metallurgical parameters are the viscosity of the liquid between the grains, $\mu$; the secondary dendrite arm spacing, $\lambda_{2} ;$ the shrinkage factor, $\beta$; and the solidification path, $f_{\mathrm{s}}(\theta)(\in[0,1])$. It is worth noting that the displacement speed of the solidification front, $\vec{v}$, from the original equation, was substituted with $\dot{\theta}$ using the following relationship ${ }^{[12]}$.

$$
\dot{\theta}=\vec{G} \cdot \vec{v}
$$

Following the arguments of Rappaz et al., ${ }^{[12]}$ Eq. [1] was evaluated between $\theta_{\text {liq }}$ and $\theta_{\text {co }}$. For convenience, $\theta_{\text {liq }}$ was used as the upper temperature limit. Sweet et al. ${ }^{[16]}$ argued that most of the pressure in the interdendritic liquid is developed at temperatures close to coalescence, and the choice of the upper temperature limit thus has a minor effect. Drezet et al. ${ }^{[18]}$ performed in situ synchrotron X-ray measurements of solidifying Al-Zn alloys. The coalescence solid fraction was found to be approximately 0.98 after the analysis of the lattice strains because of the macro-straining of the mushy zone. Easton et al. ${ }^{[19]}$ studied the predictions of the RDG model at different coalescence fractions in Al-Si-Mg alloys. They reported that the best predictions of hot tearing susceptibility were obtained with a coalescence fraction of 0.99 . Sweet et al. ${ }^{[16]}$ observed that for AA6060 with varying Fe contents over 0.1 wt. pct, the predictions of hot tear susceptibility using the RDG model at coalescence fractions of 0.98 and 0.99 are nearly identical. This is due to the presence of a eutectic transformation at the end of the solidification. Nevertheless, they observed that the RDG criterion failed to predict the actual hot tearing behavior because of the microstructural evolution of the solid skeleton during solidification for different $\mathrm{Fe}$ additions. The different microstructures of the solid skeleton with varying $\mathrm{Fe}$ contents result in different evolutions of the mechanical response of the mushy zone, and by extension, different solid fractions for coalescence. ${ }^{[16]}$ In the current study, since the composition was kept constant and the concentration of Fe was 0.44 wt. pct (Table II), the solid fraction for coalescence was set to a value of 0.98 .

According to Drezet et al., ${ }^{[13]}$ the contribution of $\dot{\varepsilon}_{\mathrm{p}}$ in Eq. [1] can be taken as the addition of the strain rates in two orthogonal directions: $\left(\dot{\varepsilon}_{x x}\right.$ and $\left.\dot{\varepsilon}_{z z}\right)$ in the plane perpendicular to $\vec{G}$. Therefore,

$$
\dot{\varepsilon}_{\mathrm{p}}=\left(\dot{\varepsilon}_{x x}+\dot{\varepsilon}_{z z}\right)_{\perp \vec{G}}
$$

In the RDG criterion, the indicator of the tortuosity in the Carman-Kozeny approximation is the secondary dendritic arm spacing for dendritic microstructures. ${ }^{[12]}$ According to Sheiki et al., ${ }^{[20]}$ if the microstructure is cellular, the primary arm spacing, $\lambda_{1}$, instead of $\lambda_{2}$, can be used as the tortuosity indicator in Eqs. [2] and [3]. 
Table II. Composition of the Base Materials Measured with Inductively Coupled Plasma (ICP)

\begin{tabular}{llllllllllll}
\hline Weight Percent & $\mathrm{Al}$ & $\mathrm{Cr}$ & $\mathrm{Cu}$ & $\mathrm{Fe}$ & $\mathrm{Ga}$ & $\mathrm{Mg}$ & $\mathrm{Mn}$ & $\mathrm{Si}$ & $\mathrm{Ti}$ & $\mathrm{V}$ & $\mathrm{Zn}$ \\
AA6061-T6 & 97.5 & 0.19 & 0.24 & 0.44 & 0.02 & 0.93 & 0.05 & 0.56 & 0.02 & 0.01 & 0.04 \\
& & & & & & & & & \\
Weight Percent & $\mathrm{Fe}$ & $\mathrm{C}$ & $\mathrm{Mn}$ & $\mathrm{Si}$ & $\mathrm{Cr}$ & $\mathrm{Al}$ & $\mathrm{Ti}$ & $\mathrm{Cu}$ & & & \\
DP980 Steel & 97.45 & 0.16 & 1.94 & 0.21 & 0.19 & 0.02 & 0.02 & 0.01 & & &
\end{tabular}

For the sake of simplicity, $\dot{\theta},|\vec{G}|$ and $\dot{\varepsilon}_{\mathrm{p}}$ were considered to be constant over the whole solidification range.

\section{THERMOMECHANICAL MODEL}

An uncoupled thermomechanical finite element model similar to the one of Tsirkas et al., ${ }^{[21]}$ was implemented in Abaqus. ${ }^{[22]} \dot{\theta}$ and $\vec{G}$ were first assessed from a heat-transfer model. $\dot{\varepsilon}_{\mathrm{p}}$ was then considered in a mechanical model using the temperature fields from the heat-transfer model as input.

\section{A. Heat-Transfer Model}

The simulation of the temperature field was adapted from the work of Crucifix et al. ${ }^{[1]}$ Four components of the weld were simulated: the steel and aluminum sheets, the backing plate, and the welding table.

The model requires the distribution of the energy input at the tool-steel interface. The power input was inferred from torque measurements at the tool during welding:

$$
P=\eta\left(T_{z} \cdot \omega\right)
$$

where $T_{z}$ is the measured torque, $\omega$ is the angular speed of the tool, and $\eta(\in[0,1])$ is the efficiency included in the heat input to account for the power loss, mainly by heat conduction through the tool. ${ }^{[23]}$

The heat source was modeled as suggested by Crucifix et al. ${ }^{[11]}$ The total power introduced in the system was divided into a surface component due to friction, $\dot{Q}_{\text {surf }}$, and a volume component due to plastic deformation of the steel below the tool, $\dot{Q}_{\mathrm{vol}}$. The surface component was distributed radially. ${ }^{[5]}$ The volume component was distributed in the steel below the tool. Half of the total power was given to each heat component, but no significant differences were observed in the temperature field of the aluminum sheet when this ratio was changed.

The material properties were chosen to be temperature dependent. The thermal conductivity and specific heat are shown in Figures 2(a) and (b) for aluminum $^{[24-27]}$ and steel, ${ }^{[24,28,29]}$ respectively. The latent heat of fusion was added to the specific heat curve as suggested by Crucifix et al. ${ }^{[1]}$ and De et al. ${ }^{[30]}$ The AA6061 solidification path shown in Figure 2(e) was taken from Meek et al. ${ }^{\text {[1] }}$

The thermal contact between the plates was divided into two regions similar to that done in Crucifix et al. ${ }^{[11]}$ i.e., a region of large thermal gap conductance and a region of small thermal gap conductance. For the large thermal gap conductance, a sufficiently high value was chosen to ensure a perfect transfer of heat through the interface, i.e., $3 \times 10^{6} \mathrm{~W} \mathrm{~m}^{-2} \mathrm{~K}^{-1}$. This value was imposed at the contacts between the steel and aluminum plates and between the aluminum and backing plates just below the tool, because of the high pressure and temperatures reached, as well as the IML bonded regions. ${ }^{[1]}$ The small gap conductance value was imposed at the rest of the contact surfaces. This parameter, together with $\eta$ in Eq. [6], were fitted to ensure the good prediction of the temperature fields.

The exposed faces were given a natural convection coefficient of $15 \mathrm{~W} \mathrm{~m}^{-2} \mathrm{~K}^{-1}$ and an emissivity of $0.3 .^{[11]}$ The entire welding table was not represented in the model. To compensate for this simplification, a higher convection coefficient of $1000 \mathrm{~W} \mathrm{~m}^{-2} \mathrm{~K}^{-1}$ was imposed on the sides to represent the continuity of the welding table.

$\dot{\theta}$ and $\vec{G}$ were extracted from the simulation in the upper element at the centerline in the aluminum at a temperature corresponding to $\theta_{\text {co }} \cdot \vec{G}$ was calculated from the heat flux, $\vec{q}$, which was obtained from the simulations at the plane of symmetry, where $\vec{q}_{y}=0$. Therefore,

$$
\vec{G}=\frac{1}{k} \cdot\left(\vec{q}_{x}+\vec{q}_{z}\right)
$$

where $k$ is the thermal conductivity of the aluminum at $\theta_{\mathrm{co}}$.

\section{B. Mechanical Model}

To calculate the strain rates during the solidification stage, the thermal field calculated by the previous model was considered as an input in a region of $30 \times 30 \mathrm{~mm}^{2}$ around the tool. The steel and aluminum plates were accounted for as deformable solids, while the tool, the backing plate and the clamps were modeled as rigid solids. The tool moved over the surface in the $x$ direction (Figure 1(a)) with a speed equal to the welding speed.

During the experiments, the plunge of the tool was set to $-0.18 \mathrm{~mm}$ into the steel. However, because of the compliance of the machine and the position inaccuracies, the real plunge of the tool was not precisely known. Therefore, the axial force measured with the dynamometer was used as an input parameter. The measured forces were applied as a vertical load on the tool. 

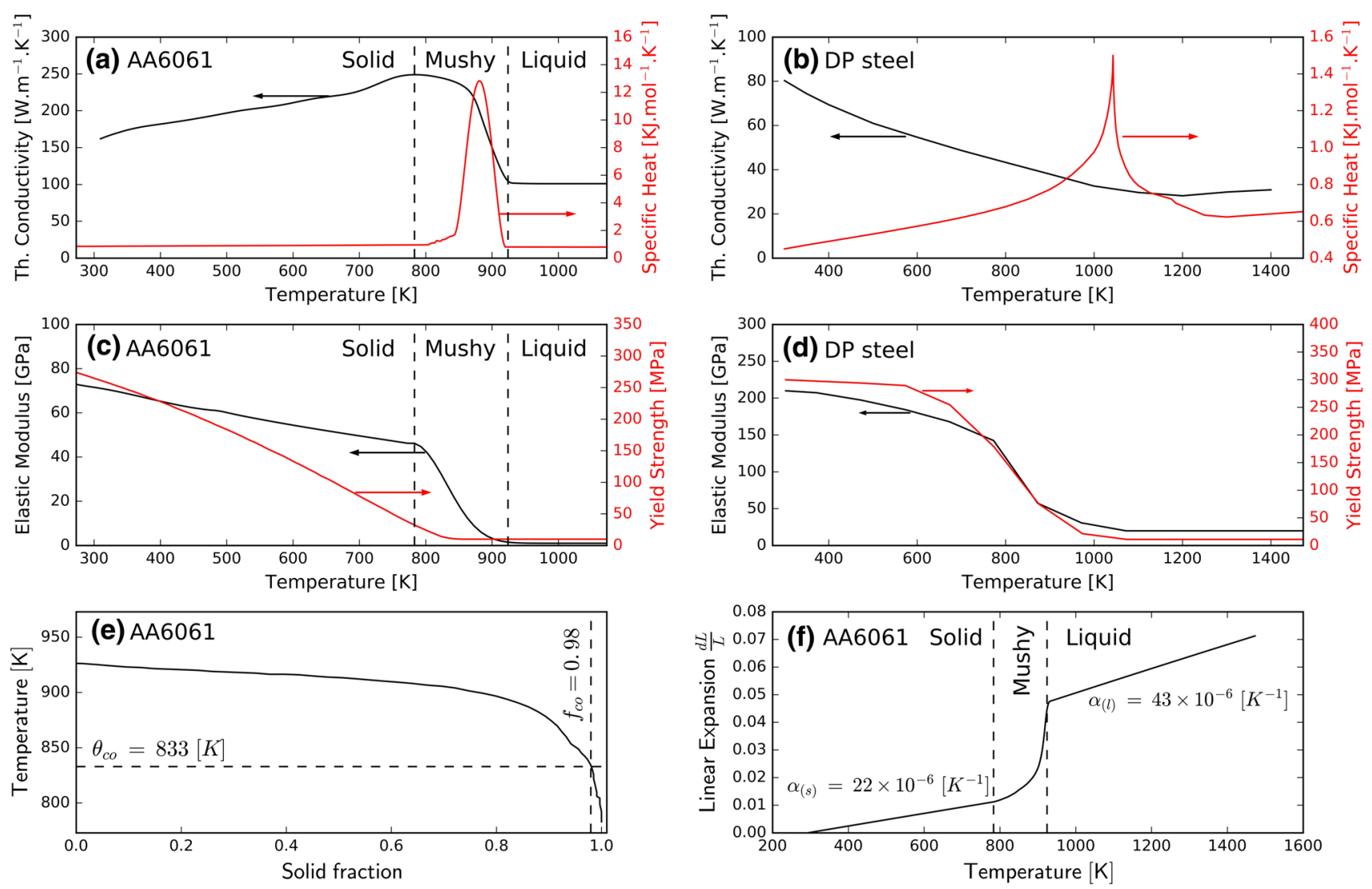

Fig. 2-AA6061 and DP980 steel properties as a function of temperature used as input in the FE model. (a) Thermal conductivity and specific heat of AA6061..$^{[24-27]}(b)$ Thermal conductivity and specific heat of DP980 steel. ${ }^{[24,28,29]}(c)$ Elastic modulus and yield stress of AA6061. ${ }^{[32]}(d)$ Elastic modulus and yield stress of DP980 steel. ${ }^{[36]}(e)$ Solidification path of AA6061. ${ }^{[31]}(f)$ Linear expansion of AA6061. ${ }^{[33,34]}$

The mechanical properties of AA6061 at high temperatures up to the melting point were taken from the work of Banerjee et al. ${ }^{[32]}$ and are shown in Figure 2(c). At high temperatures, the aluminum showed a perfectly plastic behavior. The liquid state was modeled with an artificial Young's modulus and yield strength of $1 \mathrm{GPa}$ and $10 \mathrm{MPa}$, respectively, to ease the convergence of the simulations. Lower values for the residual mechanical properties hindered the convergence in the mushy zone and at the contact between the liquid aluminum pool and the solid steel surface. To avoid the accumulation of plasticity in the liquid state, the annealing function of Abaqus $^{[22]}$ was used. This function sets the equivalent plastic deformation back to zero at temperatures above $\theta_{\text {co. }}$. The coefficient of thermal expansion of the aluminum, $\alpha$, was also temperature-dependent. For the sake of readability, instead of $\alpha$, Figure 2(f) shows the linear expansion of an element, $\frac{\mathrm{d} L}{L}$, as a function of temperature from a reference temperature of $293 \mathrm{~K}$. The elongation provided in Figure 2(f) was assembled from the coefficient of thermal expansion of the solid and liquid states ${ }^{[33,34]}$ and the shrinkage factor, $\beta \cdot \cdot^{[35]} \alpha$ was then calculated as the derivative of this curve.

The evolution of properties of the dual-phase steel 980 (DP980) at high temperatures (Figure 2(d)) was considered to be similar to those of a structural steel and was obtained from the work of Xiong et al. ${ }^{[36]}$ The DP980 steel had a constant $\alpha$ equal to $11 \times 10^{-6} \mathrm{~K}^{-1}$. ${ }^{37]}$

To model the intermetallic bonding, a thermal criterion was used. An aluminum node was bonded to the steel surface when its temperature during heating reached 913 $\mathrm{K}$, corresponding to a liquid fraction of 0.5 . However, to avoid excessive deformation of the elements of the aluminum while they are still in the liquid state, the bonding constants were only activated once the temperature decreased below $863 \mathrm{~K}$ during cooling, i.e., $25 \mathrm{~K}$ higher than $\theta_{\text {co. }}$. Indeed, at $\theta_{\mathrm{co}}$, the solid skeleton formed in the mushy zone starts to show a larger capacity to transfer load. To ease the convergence at the contact, some relative displacement was allowed between the surfaces following the Hooke's law with an elastic constant of $400 \mathrm{GPa} \mathrm{mm}^{-1}$, i.e., if the surface element penetrated $1 \mathrm{~mm}$ into the steel, it would see a compressive stress of $400 \mathrm{GPa}$. This was the highest possible value to ensure the convergence of the simulation while minimizing the relative displacement of the bonded surfaces.

$\dot{\varepsilon}_{\mathrm{p}}$ was extracted from the simulation at the upper element at the centerline in the aluminum at a temperature corresponding to $\theta_{\text {co }}$. The mushy zone only starts to behave as a solid at the coalescence temperature. ${ }^{[18]}$ Therefore, the predicted strain rates at higher temperatures are not reliable in the present model. 
Table III. Thermal Conductivity of the Backing Plates ${ }^{[38-40]}$

\begin{tabular}{lccc}
\hline & Copper ETP & Brass 70/30 & Stainless Steel 304 \\
\hline Thermal Conductivity $\left(\mathrm{W} \mathrm{m}^{-1} \mathrm{~K}^{-1}\right)$ & 350 & 120 & 14.5 \\
\hline
\end{tabular}

\section{EXPERIMENTAL PROCEDURE}

The base materials were AA6061-T6 and DP980 with respective thicknesses of 3.1 and $0.8 \mathrm{~mm}$. Their compositions are provided in Table II. The plates were cut down to a size of $250 \times 80 \mathrm{~mm}$. A 5-mm-thick backing plate was placed below this stack (Figure 1(a)). The full stack was subsequently clamped to the welding table.

Welds were carried out on a Hermle milling machine. The tool was a simple cylinder made of cemented tungsten carbide (WC-Co) with a diameter of $16 \mathrm{~mm}$. The tool had a backward tilting angle of $0.5 \mathrm{deg}$, and its rotational speed was set to $2000 \mathrm{rpm}$. Temperatures were recorded during welding using K-type thermocouples. A schematic of the thermocouples positioning is provided in the Supplementary Material. The torque and forces on the tool during welding were recorded using a Kistler dynamometer. The range of tested thermomechanical cycles was determined by modifying two parameters, the welding speed $(100,150,200$ and $250 \mathrm{~mm} \mathrm{~min}{ }^{-1}$ ) and the material of the backing plate (copper, brass, and stainless steel) with thermal conductivities provided in Table III and extracted from References 38-40. For the metallurgical observations, two welds per condition were carried out for a total of 24 . The combination of a copper backing plate and a welding speed of $200 \mathrm{~mm} \mathrm{~min}^{-1}$ was studied in more detail and eight extra welds were performed. The calibration of the thermomechanical model was performed for welding speeds of 100, 200, and $400 \mathrm{~mm} \mathrm{~min}{ }^{-1}$ so that two extra welds were performed at $400 \mathrm{~mm} \mathrm{~min}^{-1}$ per backing plate for a total of 6 .

The microstructure of the aluminum plate was revealed using a $0.5 \mathrm{M} \mathrm{NaOH}$ solution. Observations were carried out by light microscopy. Additional EBSD measurements were carried out.

\section{RESULTS}

\section{A. Microstructure}

Figure 3 shows the light microscopy observations of longitudinal sections performed at the weld centerline for all the tested parameters. The different welds performed with stainless steel and brass backing plates present hot tearing. On the other hand, welds performed using a copper backing plate do not show hot tears for most of the parameters. Solely, the welds performed at a welding speed of $200 \mathrm{~mm} \mathrm{~min}^{-1}$ using a copper backing plate present a near 60 pct probability of hot tearing around.
In most cases, hot tears propagate close to the interface with the steel. However, Figures 3(c) and (d) show that the propagation of a hot tear can also occur in the bulk of the molten pool and that several hot tears can propagate in parallel.

Figure 4(a) shows the position of a hot tear with respect to the boundaries of the molten pool. The extent of hot tearing is limited to the molten pool, i.e., no such tears are observed in the partially melted zone. Figure 4(b) shows an EBSD map illustrating the nucleation site of a hot tear. It can be observed that the hot tear does nucleate and propagate along a grain boundary. This is in line with the theory developed by Rappaz et al. ${ }^{[12]}$

As explained in the section describing the RDG criterion, either the primary or secondary arm spacing was measured in the case of cellular or dendritic microstructures, respectively. Figure 5 illustrates how these parameters were estimated. Whether the microstructure is dendritic or cellular depends on the nature of the backing plate. Dendrites are dominant in welds performed with stainless-steel and brass backing plates (Figure 5(a)), while cells are dominant in welds performed with a copper backing plate (Figure 5(b)). Figure 6(a) summarizes the measured $\lambda_{1}$ and $\lambda_{2}$ spacings as a function of the cooling rate, $\dot{\theta}$, predicted by the simulations. Figure 6(b) maps the domains of dendritic and cellular microstructures as a function of the speed of the solidification front, $|\vec{v}|$, and the thermal gradient, $|\vec{G}|$, predicted by the simulations.

\section{B. Torque and Force Measurements}

Figure 7(a) presents the power input inferred from the torque measurements under steady-state conditions (Eq. [6]). It varies as a function of the welding speed and the nature of the backing plate. It is worth noting that these measurements were carried out for welding speeds of 100,200 , and $400 \mathrm{~mm} \mathrm{~min}^{-1}$ instead of the $100,150,200$, and $250 \mathrm{~mm} \mathrm{~min}{ }^{-1}$ used throughout the rest of the current study. The unavailable power inputs are interpolated from the available data. The drop in power input observed for a copper backing plate at welding speeds of 300 and $400 \mathrm{~mm} \mathrm{~min}{ }^{-1}$ is explained by the lack of fusion of the aluminum. These conditions lead to no bonding, so they were not considered any further. Similarly, the measured axial forces depend on both the welding speed and the nature of the backing plate (Figure 7(b)). In this case, there is no drop of axial force associated with the lack of fusion of the aluminum as observed in the torque measurements. 


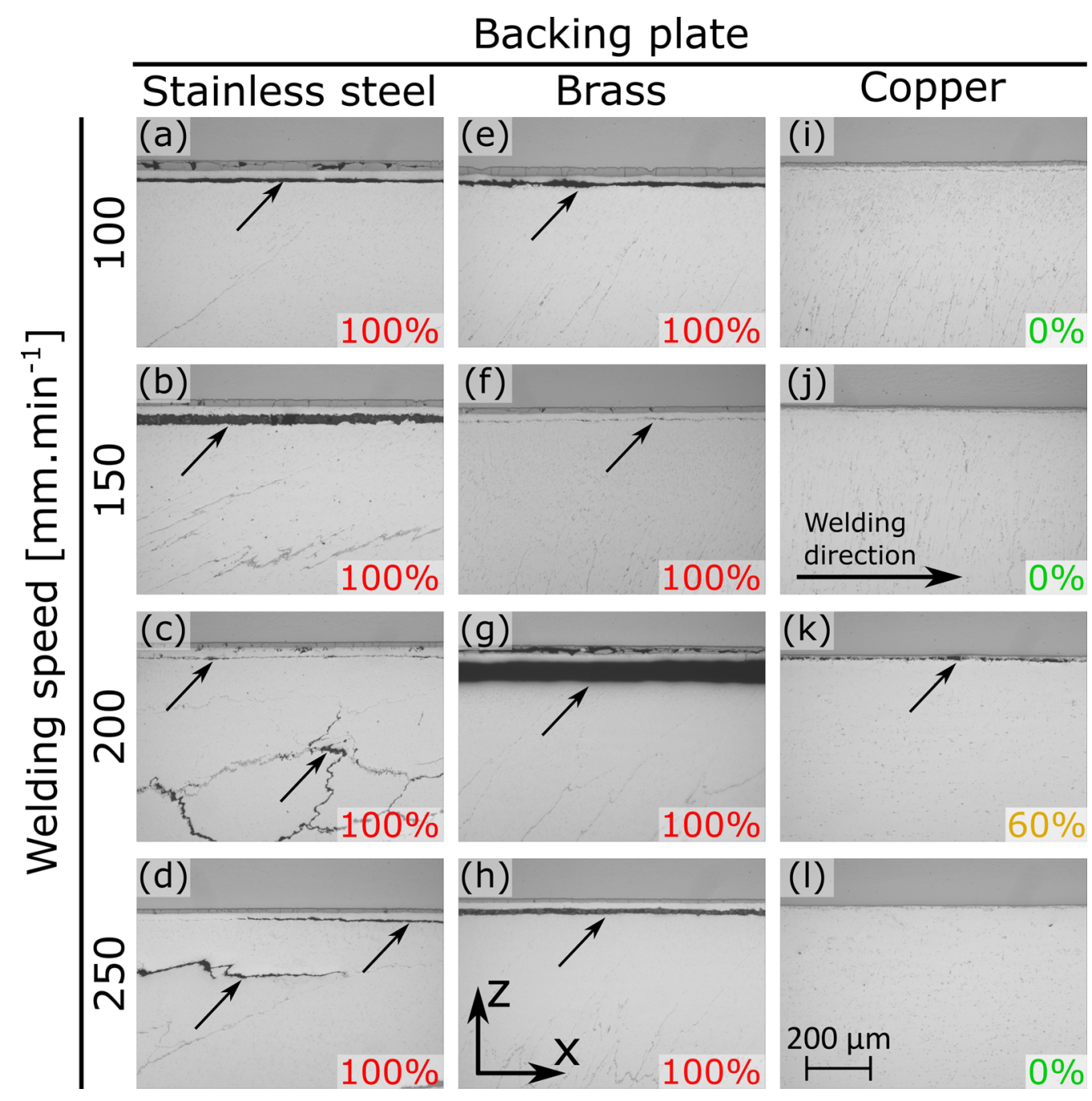

Fig. 3-Light microscopy observations of the longitudinal sections at the weld centerline for all studied welding parameters. $(a, b, c, d)$ Welds performed with a stainless steel backing plate. $(e, f, g, h)$ Welds performed with a brass backing plate. $(i, j, k, l)$ Welds performed with a copper backing plate. The welding speed is $100 \mathrm{~mm} \mathrm{~min}^{-1}$ in $(a, e, i), 150 \mathrm{~mm} \mathrm{~min}^{-1}$ in $(b, f, j), 200 \mathrm{~mm} \mathrm{~min}$ in $^{-1}(c, g, k)$ and $250 \mathrm{~mm} \min ^{-1}$ in $(d, h$, l). Black arrows indicate the position of hot tears. The probability of occurrence of hot tears for each combination of parameters is also indicated.

\section{Calibration and Validation of the Thermal Model}

The calibration of the thermal model was performed using the temperature measurements. A manual optimization procedure was carried out to correctly predict the temperature fields for all measurements. The two unknown constants of the model, the low thermal gap conductance and the efficiency of the power input of the tool, are found to be $30 \mathrm{~kW} \mathrm{~m}^{-2} \mathrm{~K}^{-1}$ and 0.89 , respectively. The value of the efficiency is close to the one found by Crucifix et al. ${ }^{[11]}$

The temperature profiles measured by the thermocouple located at the aluminum-backing plate interface at the weld centerline (T1 in the Supplementary Material) are compared for the three different backing plates in Figure 8(a). This thermocouple is the closest one to the molten pool. The simulations reproduce the measurements fairly well. Figure 8(b) shows a comparison of the thermocouples placed on the advancing and retreating sides of a weld (T2-T7 in the Supplementary Material) performed at $200 \mathrm{~mm} \mathrm{~min}{ }^{-1}$ for a brass backing plate. The retreating side of the weld shows a low maximum temperature when compared with the advancing sides. The maximum difference of approximately $10 \mathrm{~K}$ between the retreating and advancing sides is considered to have a minor effect on the following prediction of hot tearing. The temperature fields away from the weld centerline are well predicted for temperatures greater than $423 \mathrm{~K}$. At lower temperatures, the temperature fields are overestimated, likely due to the simplified thermal contacts between the plates. However, the low temperature predictions are not critical in the assessment of hot tears.

The model is also validated by comparing the direction of the growth of grains and the thickness of the molten pool at the weld centerline, as shown in Figures 9(d) and (e). During solidification, grains grow 
in the direction of the maximum temperature gradient (Figure 1(b)). The experimental values were measured at the weld centerline from longitudinal cross sections after polishing and etching (Figures 9(b) through (d)). From the simulations, the direction of $\vec{G}$ is calculated at 0.1 $\mathrm{mm}$ below the interface at a temperature of $913 \mathrm{~K}$,

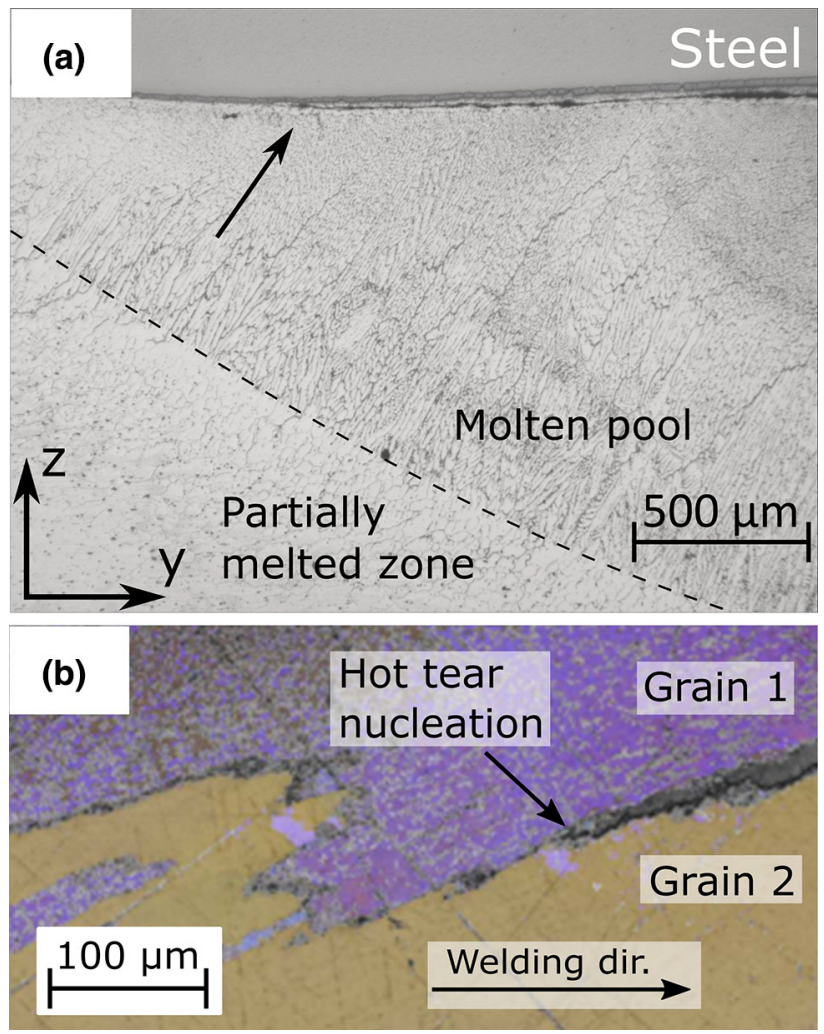

Fig. 4-(a) Light microscopy observation of a transversal section of a weld performed at $100 \mathrm{~mm} \mathrm{~min}^{-1}$ on a brass backing plate. The black arrow indicates the position of the hot tear, which is found in the molten pool. (b) EBSD map of a longitudinal section showing the nucleation of a hot tear in the aluminum molten pool between two grains on a weld performed at $250 \mathrm{~mm} \mathrm{~min}^{-1}$ on a stainless steel backing plate. corresponding to a solid fraction of 0.5 . The thickness of the molten pool at the weld centerline is measured as the distance between the interface and the lower point where the columnar microstructure ends. In the simulations, the boundaries of the molten pool are defined at a temperature corresponding to a solid fraction of 0.5 . The overall behavior of the growth is well captured by the simulations. This confirms that the thermal model describes the thermal fields reasonably well and can thus be used to predict the hot tearing formation.

\section{Thermomechanical Simulations}

The results for $\dot{\theta}, \vec{G}$, and $\dot{\varepsilon}_{\mathrm{p}}$ are shown in Figures $10(\mathrm{a})$ through (c). $\dot{\theta}$ (Figure 10(a)) increases with the increasing conductivity of the backing plate and the increasing welding speed. $|\vec{G}|$ (Figure 10(b)) depends mainly on the nature of the backing plate, while the effect of the welding speed is negligible. The largest values of $|\vec{G}|$ are achieved with a copper backing plate and the lowest one with a stainless-steel backing plate. The highest values of $\dot{\varepsilon}_{\mathrm{p}}$ are found for the copper backing plate, then brass and finally stainless steel (Figure 10(c)). The effect of the welding speed is only clear in the case of the copper backing plate, but no major influence is observed for the brass and stainless-steel backing plates.

\section{E. Drop of Pressure}

Figure 10(d) shows the results for $\Delta p$ after evaluating Eq. [1] between $\theta_{\text {co }}$ and $\theta_{\text {liq }}$ using the predictions reported in Figures 10(a) through (c). The highest values of $\Delta p$ are found when using brass and stainless-steel backing plates, while the lowest ones are found for the copper backing plate. This is in agreement with the experimental observations. Hot tears are systematically found when using a brass or stainless-steel backing plate. On the other hand, hot tears are not observed when using a copper backing plate except sometimes for a welding speed of $200 \mathrm{~mm} \mathrm{~min}^{-1}$. Indeed, the $\Delta p$ curve
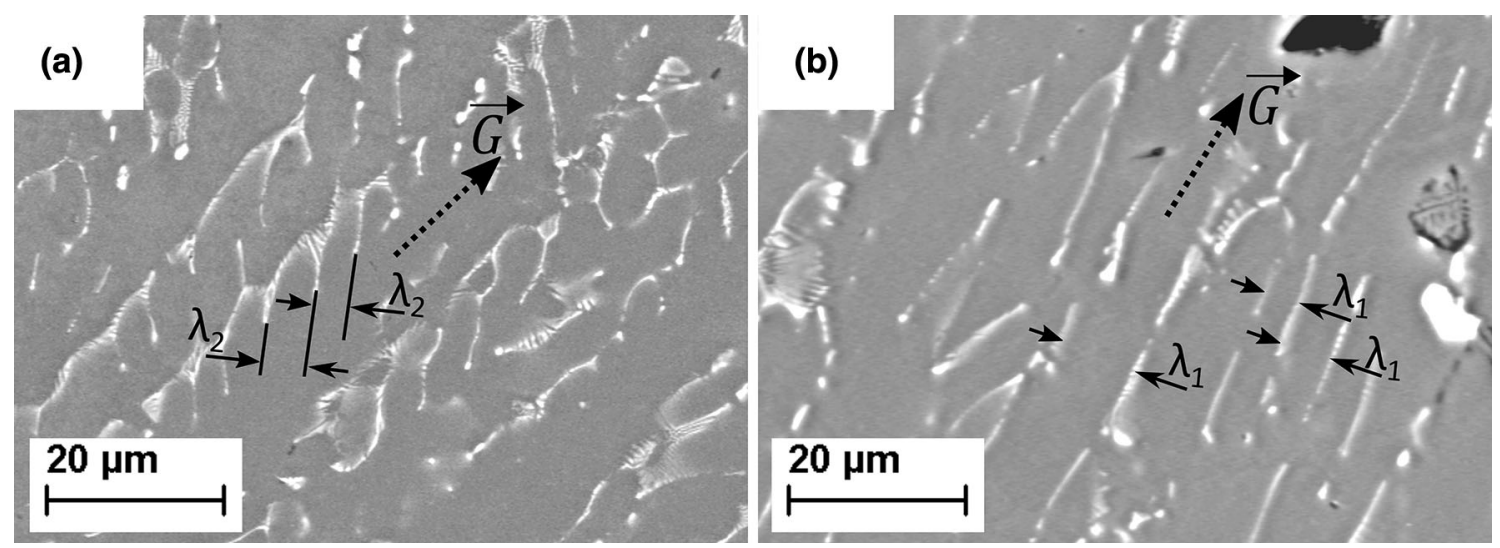

Fig. 5-SEM observations of a longitudinal cross section of the molten pool for a weld performed on a $(a)$ stainless-steel backing plate and $(b)$ copper backing plate for a welding speed of $150 \mathrm{~mm} \mathrm{~min}^{-1} . \lambda_{2}$ for dendritic grains is measured as the thickness of the secondary dendrite arms. $\lambda_{1}$ for cellular grains is measured as the diameter of the cell. The direction of grain growth is indicated by $\vec{G}$. 


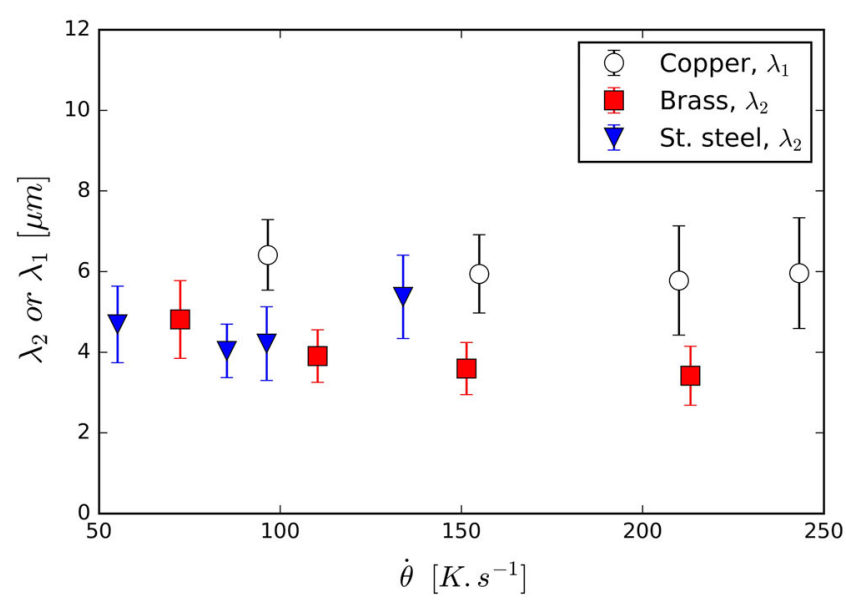

(a)

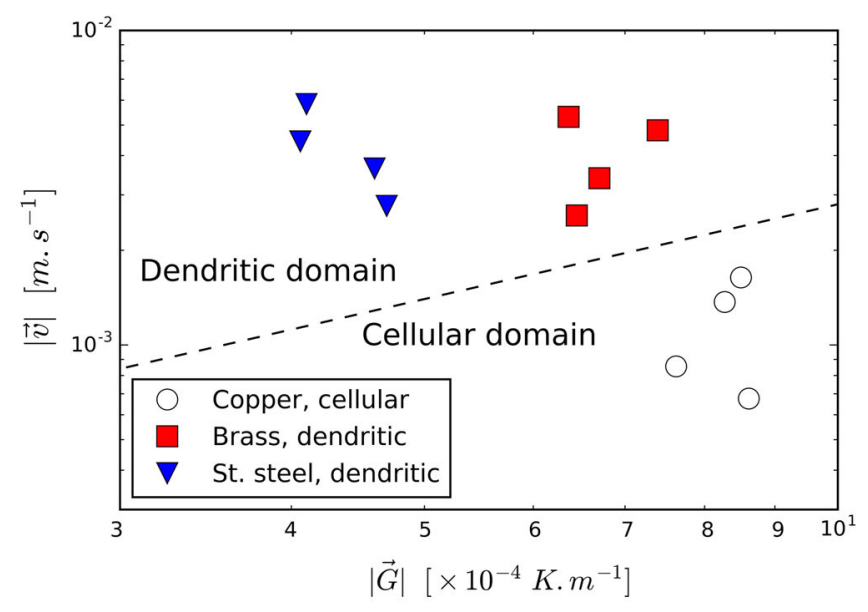

(b)

Fig. 6 - (a) Evolution of the secondary dendrite arm spacing, $\lambda_{2}$, or primary arm spacing, $\lambda_{1}$, on welds performed with various backing plates, as a function of $\dot{\theta}$. (b) Boundary between the dendritic and cellular dominated microstructure domains as a function of $|\vec{v}|$ and $|\vec{G}|$. The dashed line delimiting the domains has a slope of $45 \mathrm{deg}$ as suggested in the work of Kurz et al. ${ }^{[42]}$

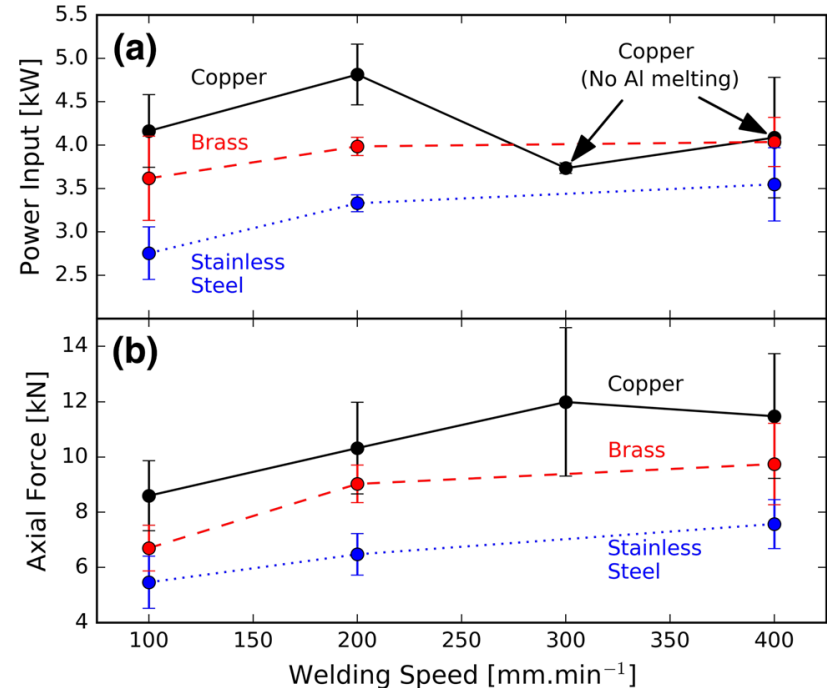

Fig. 7-Evolution of (a) power input inferred from torque measurements (using Eq. [6]), and (b) axial force on the tool for different backing plates and welding speeds.

for the copper backing plate shows a maximum at that welding speed.

\section{DISCUSSION}

\section{A. Torque and Force}

The increment of torque and axial force with the increasing welding speed and thermal conductivity of the backing plate can be explained following the arguments of Buchibabu et al. ${ }^{[1]}$ With high welding speeds and a highly conductive backing plate, the maximum temperatures reached are low. The flow stresses are thus high, and the tool requires more energy
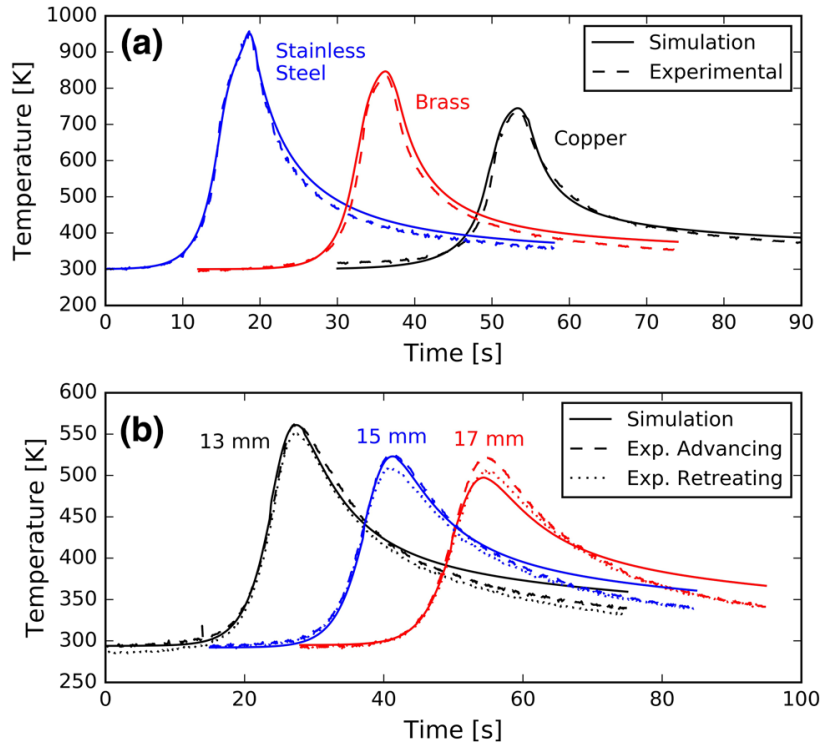

Fig. 8 - Comparison of the thermocouple measurements and simulated thermal fields. (a) Temperature profiles at the interface between the aluminum plate and the backing plate at the weld centerline for a welding speed of $200 \mathrm{~mm} \mathrm{~min}^{-1}$ for the copper, brass, and stainless-steel backing plates. (b) Temperature profiles at different lateral distances from the weld centerline on the advancing and retreating sides of a weld performed at $200 \mathrm{~mm} \mathrm{~min}^{-1}$ on a brass backing plate. The thermocouple positioning is provided in the Supplementary Material.

to induce plastic deformation of the steel plate. This results in a higher torque and axial force.

\section{B. Microstructure}

The observations of the longitudinal sections provided in Figure 3 reveal that hot tears in FMB generally propagate close to the interface with steel, at a distance below $40 \mu \mathrm{m}$. Nevertheless, two hot tears can grow in 


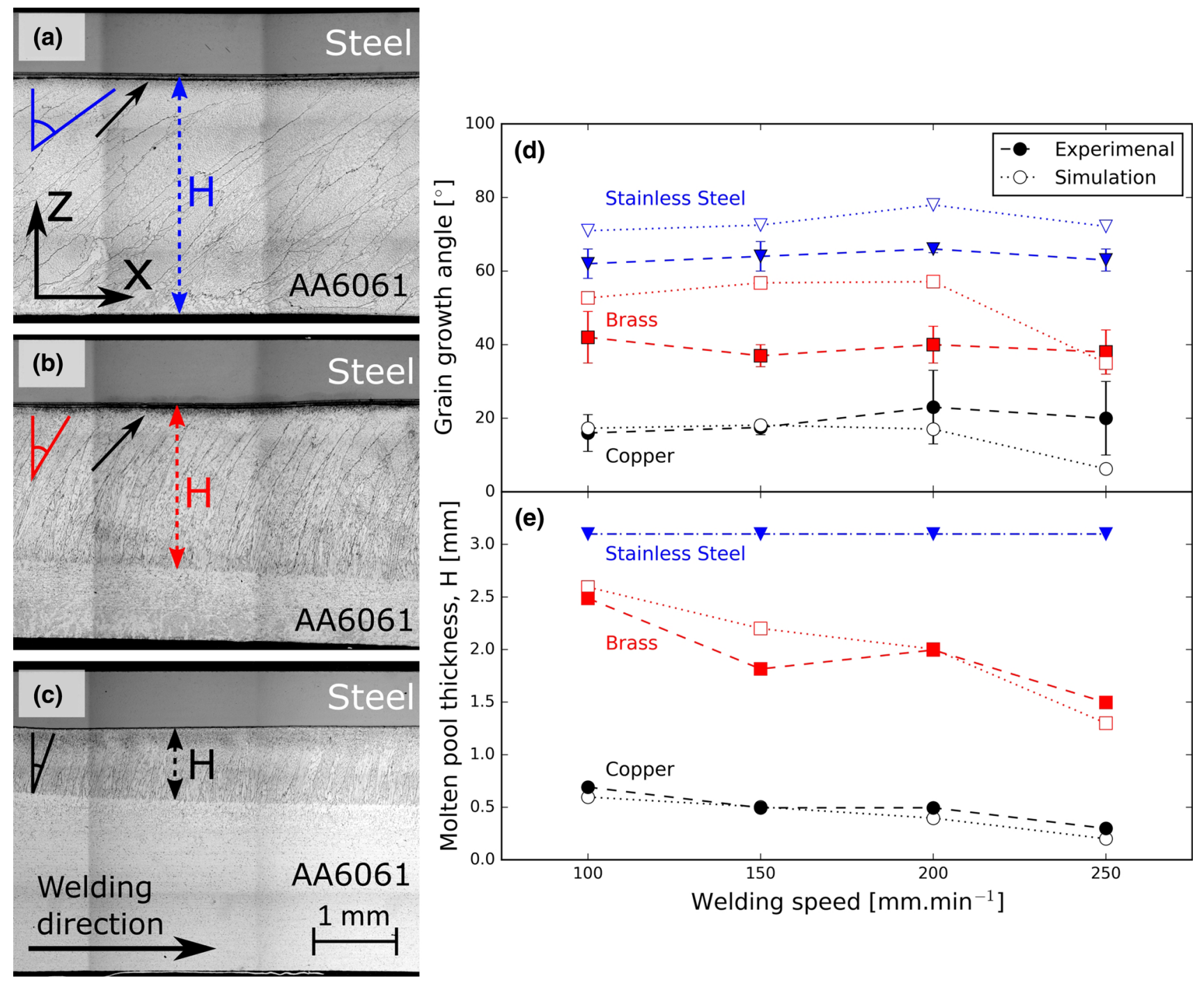

Fig. 9- $(a, b, c)$ Longitudinal cross sections after etching of the weld centerline for welds performed on stainless-steel, brass, and copper backing plates, respectively, for a welding speed of $100 \mathrm{~mm} \mathrm{~min}^{-1}$. The black arrows indicate the position of hot tears. ' $\mathrm{H}$ ' denotes the thickness of the molten pool revealed after etching. (d) Comparison of the predicted grain growth directions with the measurements performed on etched sections. (e) Comparison of the predicted molten pool thicknesses, $\mathrm{H}$, with the measurements performed on etched longitudinal cross sections.

parallel as shown in Figure 3(c), or stop and nucleate elsewhere, as shown in Figure 3(d). Figure 4(a) shows that hot tears are situated in the molten pool. They cannot be attributed to liquidation cracking since all cracks are confined to a zone that has been fully melted. ${ }^{[43]}$

According to Kurz et al. ${ }^{[42]}$ the formation of either a cellular or a dendritic microstructure is determined by $|\vec{v}|$ and $|\vec{G}|$. These variables are plotted in Figure 6(b), where the transition between cellular and dendritic microstructure is in agreement with the transition described by Kurz et al. ${ }^{[42]}$ To form cells instead of dendrites, $|\vec{G}|$ has to increase while $|\vec{v}|$ has to decrease. This condition is met with the use of a copper backing plate.

Cho et al. ${ }^{[44]}$ investigated the evolution of $\lambda_{2}$ in Al-Si alloys as a function of $\dot{\theta}$ in pressure die casting. They observed that for cooling rates over $100 \mathrm{~K} \mathrm{~s}^{-1}, \lambda_{2}$ is lower than $10 \mu \mathrm{m}$. This is in line with measurements of Figure 6(a) that showed that, for welds performed on stainless-steel and brass backing plates, $\lambda_{2}$ ranges from 3 to $5 \mu \mathrm{m}$.

\section{Effect of the Welding Condition on the Thermomechanical Cycles}

Figure 10 shows that the calculated values of $\dot{\theta}, \vec{G}, \dot{\varepsilon}_{\mathrm{p}}$, and $\Delta p$ are highly dependent on the nature of the backing plate. According to Eq. [1], a low $\dot{\theta}$ decreases the risk of hot tearing, which is achieved with a low thermal conductivity backing plate (e.g., stainless steel). This is attributed to the low heat pumping capacity of the backing plate, which keeps the heat in the aluminum plate. The brass and copper backing plates show a larger thermal conductivity, and therefore, a larger $\dot{\theta}$, which also increases with the welding speed. This is due to the lower temperature reached by the surroundings of the 


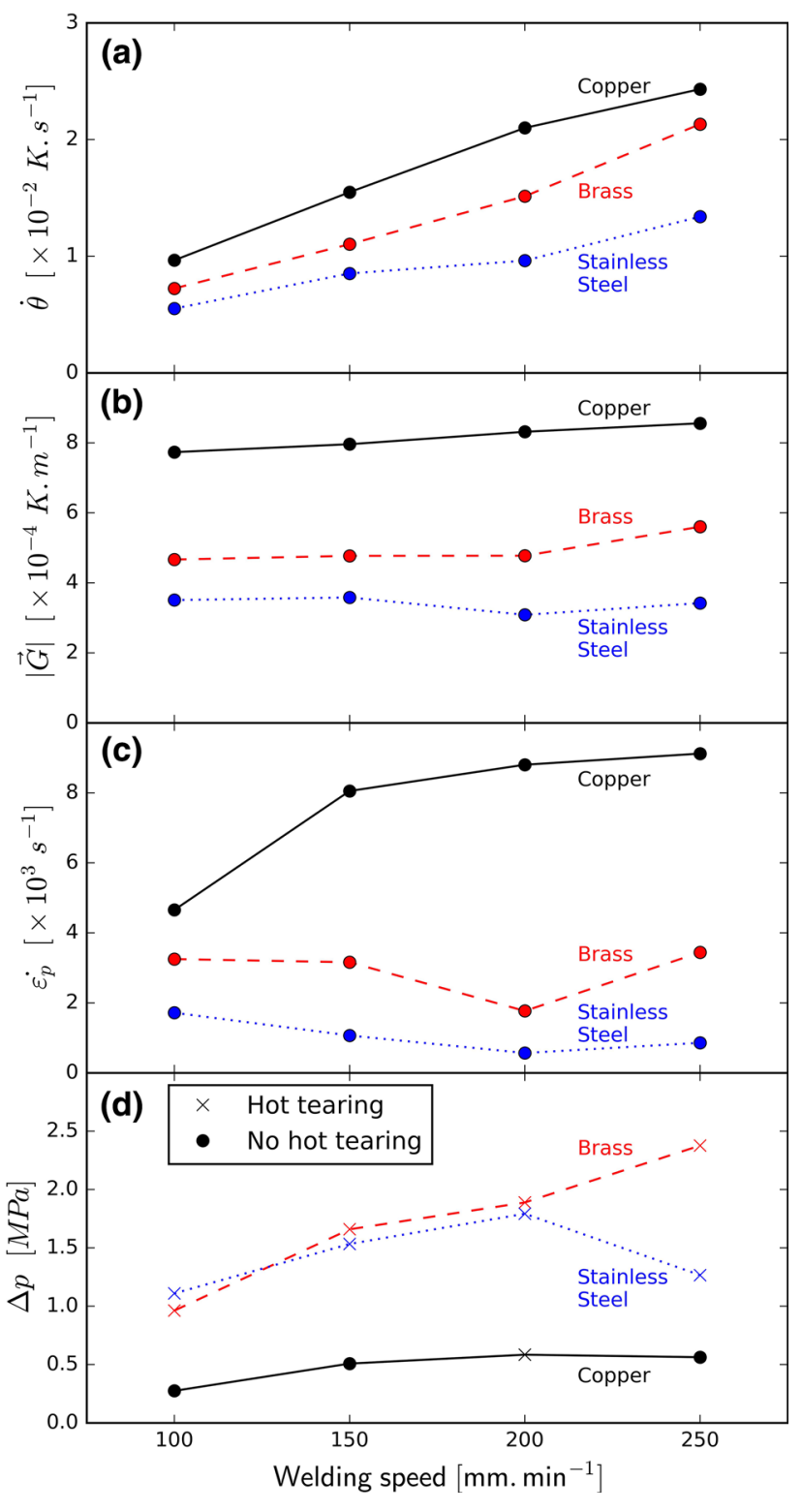

Fig. 10-Evolution of the thermomechanical cycles in the mushy zone as a function of the welding speed and the backing plate: $(a) \dot{\theta}$, (b) $|\vec{G}|$, (c) $\dot{\varepsilon}_{\mathrm{p}}$, and (d) $\Delta p$. The crosses in (d) denote the welding conditions that led to the formation of hot tears, while the circles denote the parameters where no hot tears were observed in the aluminum.

molten pool at higher welding speeds, which results in a larger heat pumping from the molten pool, and hence, a larger $\dot{\theta}$.

$\mid \vec{G}$ is inversely proportional to the distance from the tip to the root of the dendrites. Therefore, the higher the thermal gradient, the shorter the distance the liquid has to travel from the tip to the root of the dendrites and the lower the risk of hot tearing. This distance, $d$, can be calculated as $d=\left(\theta_{\text {liq }}-\theta_{\text {co }}\right) /|\vec{G}|$. Using the values of Figure 10(b), this yields values of $d$ on the order of 1.3 , 1.9 , and $2.4 \mathrm{~mm}$ for the copper, brass, and stainless-steel backing plates, respectively. The distance the liquid has to cover with a copper backing plate is thus roughly half of the distance in the case of a stainless-steel one. Since $|\vec{G}|$ mainly depends on the thermal conductivity of the backing plate, a larger thermal conductivity of the backing plate directly leads to a larger $|\vec{G}|$. To achieve a large $|\vec{G}|$ that reduces the hot tearing risk, the temperature difference between the top and the bottom of the aluminum plate should be maximized. This condition is met with a copper backing plate, as shown by Figures 7(a) and 8(a).

On the other hand, according to Eq. [1], $\dot{\varepsilon}_{\mathrm{p}}$ should be as small as possible to reduce the risk of hot tearing. It is observed that the use of a stainless-steel backing plate leads to low strain rates compared with those of the brass and copper backing plates. This is explained by the low cooling rates and the high temperatures that are reached. The contraction rates of the surrounding material are proportional to $\dot{\theta}$. Therefore, low cooling rates lead to low strain rates, as in the case of a stainless-steel backing plate. In addition, the surrounding material is at a higher temperature, which means that the flow stresses are lower. This results in a less effective loading of the mushy zone by the contraction of the surrounding material, and therefore, in lower strain rates. On the other hand, the use of a copper backing plate leads to larger cooling rates and lower temperatures, which result in larger $\dot{\varepsilon}_{\mathrm{p}}$. One of the reasons explaining the high values of $\dot{\varepsilon}_{\mathrm{p}}$ for a copper backing plate is that the entire thickness of the aluminum plate does not melt as in the case of brass and stainless-steel backing plates. If the entire plate thickness melts, it can better accommodate the contraction deformations.

\section{Hot Tearing Prediction}

Drezet et al. ${ }^{[13]}$ and Tian et al. ${ }^{[14]}$ used the maximum allowable strain rate, $\dot{\varepsilon}_{\text {p,max }}$, as a criterion to predict the formation of hot tears. In their work, $\dot{\varepsilon}_{\mathrm{p}, \max }$ was estimated from the simulated thermal cycles by imposing a critical $\Delta p$ level for cavitation. In the current study, $\Delta p$ is not imposed but estimated from the thermomechanical simulations, which allows for an independent view of the effect of the thermomechanical parameters from Eq. [1].

$\Delta p$ is mainly sensitive to the choice of the backing plate (Figure 10(d)). The lowest values of $\Delta p$ are reached with a copper backing plate. This is counterintuitive at first since $\dot{\theta}$ and $\dot{\varepsilon}_{\mathrm{p}}$ are significantly larger using a copper backing plate. The hot tearing risk increases with the increasing cooling rates because of (i) the larger transformation rate of liquid to solid, determined by the solidification path provided in Figure 2(c); and (ii) the larger strain rates that tear apart the grains. A first-order approximation of the strain rates in the mushy zone because of the thermal contraction of the aluminum plate can be assessed as $\dot{\varepsilon}=\dot{\theta} \cdot \alpha_{\mathrm{Al}}$, where $\dot{\varepsilon}$ is the strain rate, $\dot{\theta}$ is the cooling rate, and $\alpha_{\mathrm{Al}}$ is the coefficient of 
thermal expansion of solid aluminum. Therefore, the large cooling rates found with the copper backing plate should increase the risk of hot tearing formation. However, the observations reveal the opposite; the hot tearing occurrence decreases when using a copper backing plate. The choice of a copper backing plate also increases $|\vec{G}|$ and $\lambda_{1}$, which reduces the risk of nucleation of hot tears. In Eq. [1], the dependencies of $\Delta p$ on $|\vec{G}|$ and $\lambda_{1}$ are squared, while the dependencies on $\dot{\theta}$ and $\dot{\varepsilon}_{\mathrm{p}}$ are linear. The large values of $\dot{\varepsilon}_{\mathrm{p}}$ and $\dot{\theta}$ reached with the copper backing plate can thus be largely compensated for by the contributions of $|\vec{G}|$ and $\lambda_{1}$. It is worth noting that the use of a copper backing plate promotes a cellular microstructure whose descriptor, $\lambda_{1}$, is slightly larger than the descriptor of the dendritic microstructure, $\lambda_{2}$, found with stainless-steel and brass backing plates, respectively. Since the descriptor $\left(\lambda_{1}\right.$ or $\lambda_{2}$ ) is squared in Eq. [1], the slightly larger values measured for the copper backing plate reduce the risk of hot tearing (Figure 6(a)).

The welding speed plays a role in the tuning of parameters. van der Rest et al. ${ }^{[9]}$ and Crucifix et al. ${ }^{[11]}$ already observed that the number of hot tears increased with the increasing welding speed. Crucifix et al. ${ }^{[1]}$ stated that the decreasing size of the molten pool as the welding speed increases is responsible for the increasing number of hot tears. This statement is true if the welding speed increases and the backing plate remains unchanged. Taking the brass backing plate as an example, Figure 9(e) shows that the size of the molten pool decreases as the welding speed increases. In this case, Figure 10(d) reveals that $\Delta p$ increases with the decreasing molten pool size. However, the statement of Crucifix et al. ${ }^{[11]}$ is not true if the nature of the backing plate changes. The size of the molten pool decreases with the increasing thermal conductivity of the backing plate (Figure 9(e)), while $\Delta p$ decreases. Therefore, the use of the size of the molten pool as a criterion to predict the formation of hot tears is inappropriate. This is revealed when the nature of the backing plate is changed.

In the case of a copper backing plate, $\Delta p$ shows a maximum for a welding speed of $200 \mathrm{~mm} \mathrm{~min}^{-1}$ (Figure 10(d)). This is in agreement with the experimental observations that reveal the formation of hot tears in 60 pct of the welds only for this speed. Therefore, it can be stated that the critical $\Delta p$ in FMB for this choice of base materials, dimensions, welding parameters, and analysis is approximately $0.5 \mathrm{MPa}$.

Rappaz et al. ${ }^{[12]}$ computed a critical $\Delta p$ on the order of $1 \mathrm{kPa}$ to nucleate a hot tear in $\mathrm{Al}-\mathrm{Cu}$. In the case of FMB, the estimated critical $\Delta p$ of $0.5 \mathrm{MPa}$ is nearly three orders of magnitude higher. This difference can be mainly explained by the value of $\lambda_{2}$ (or $\lambda_{1}$ ), which is squared in Eq. [1]. Rappaz et al. ${ }^{[12]}$ computed $\Delta p$ using $\lambda_{2}=100 \mu \mathrm{m}$, which is substantially larger than the mean value of $6 \mu \mathrm{m}$ estimated from Figure 6(a).

The large values of $\Delta p$ are in agreement with the process features. The expansion of the aluminum melt is constrained between the solid aluminum and the steel plate under the pressure of the tool. Since no liquid aluminum leaks out from the molten pool, the pressure rises, the hot tearing susceptibility decreases, and a larger $\Delta p$ is thus needed to nucleate a hot tear. However, the presence of hot tears when welding on stainless-steel and brass backing plates is an indicator that the pressure rise in the molten pool is limited since large pressure increases would inhibit the hot tear formation. The increase of pressure is lowered by the deformation of the surroundings of the molten pool (steel and solid aluminum). The latter are easily deformed by the expanding aluminum because of (i) the low compressibility of liquid aluminum, ${ }^{[45]}$ and (ii) the lowered mechanical properties of steel and solid aluminum from the high temperatures that are reached.

In addition, the presence of a steel plate in contact with the liquid and solidified aluminum limits the deformations at the interface. This is explained by the higher stiffness and lower thermal expansion coefficients of the steel compared with the aluminum in both its solid and liquid states.

It could be suggested that, according to the tendencies shown in Figure 10(d), reducing the welding speed with the brass and stainless-steel backing plates would reduce $\Delta p$. However, tests at such low welding speeds were unsuccessful since the quality of the weld was not good enough because of the reaction of the molten aluminum with the backing plate.

\section{CONCLUSION}

The hot tearing phenomenon has been explored in the dissimilar friction melt bonding (FMB) of aluminum to steel using finite-element simulations and the RDG criterion. The effects of the welding speed and the influence of the material of the backing plate have been investigated.

The pressure drop at the root of the grains has been used as a criterion to evaluate the risk of the formation of hot tears. The drop of pressure was inferred from the cooling rates, thermal gradients, and strain rates in the mushy zone from finite-element simulations. Despite the highest cooling and strain rates, the use of a copper backing plate reduces the risk of formation of hot tears. In line with the RDG criterion, the dominant process parameter that reduces the risk of hot tearing formation is the large thermal gradient induced with a copper backing plate.

The use of a copper backing plate also results in a cellular solidification microstructure, rather than the dendritic microstructures obtained with the stainless-steel and brass backing plates. The measured tortuosity descriptor for cellular microstructures, the primary arm spacing, is slightly larger than the descriptor for dendritic microstructures, the secondary arm spacing, thereby reducing the hot tearing risk.

Because of the rise of pressure in the molten pool during the constrained expansion of the liquid aluminum, a higher drop of pressure compared with other processes, such as casting, is required to nucleate a hot 
tear in the friction melt bonding process. The model correctly predicts this behavior, and the critical pressure drop is shown to be approximately $0.5 \mathrm{MPa}$.

\section{ACKNOWLEDGMENTS}

The authors acknowledge the financial support of the Interuniversity Attraction Poles Program from the Belgian State through the Belgian Policy agency, contract IAP7/21 INTEMATE. N. Jimenez-Mena acknowledges the financial support of FRIA, Belgium. A. Simar acknowledges the financial support (from January 2017) of the European Research Council (ERC) under European Union's Horizon 2020 research and innovation program (Grant Agreement No. 716678).

\section{ELECTRONIC SUPPLEMENTARY MATERIAL}

The online version of this article (https://doi.org/10. 1007/s11661-018-4618-z) contains supplementary material, which is available to authorized users.

\section{REFERENCES}

1. X. Cui, H. Zhang, S. Wang, L. Zhang, and J. Ko: Mater. Des., 2011, vol. 32, pp. 815-21.

2. U. Dilthey and L. Stein: Weld. Join., 2006, vol. 11, pp. 135-42.

3. M. Potesser, T. Schoeberl, H. Antrekowitsch, J. Bruckner: EPD Congr., 2006, pp. 167-76.

4. T. Tanaka, T. Morishige, and T. Hirata: Scripta Mater., 2009, vol. 61 , pp. $756-59$.

5. A. Simar, J. Lecomte-Beckers, T. Pardoen, and B. de Meester: Sci. Technol. Weld. Join., 2006, vol. 11, pp. 170-77.

6. A. Simar and M.-N. Avettand-Fènoël: Sci. Technol. Weld. Join., 2016, vol. 1718, pp. 1-15.

7. M. Kimura, H. Ishii, M. Kusaka, K. Kaizu, and A. Fuji: Sci. Technol. Weld. Join., 2009, vol. 14, pp. 388-95.

8. H. Ozaki, M. Kutsuna, S. Nakagawa, and K. Miyamoto: J. Laser Appl., 2010, vol. 22, pp. 1-2.

9. C. Van Der Rest, P.J. Jacques, and A. Simar: Scripta Mater., 2014, vol. 77 , pp. $25-28$

10. C. Van Der Rest, A. Simar, and P.J. Jacques: International Publication No. WO2013164294 (A1) (patent), 7 November 2013.

11. S. Crucifix, C. Van Der Rest, N. Jimenez-Mena, P.J. Jacques, and A. Simar: Sci. Technol. Weld. Join., 2015, vol. 20, pp. 319-24.

12. M. Rappaz, J. Drezet, and M. Gremaud: Metall. Mater. Trans. A, 1999, vol. 30A, pp. 449-55.

13. J.M. Drezet and D. Allehaux: Hot Cracking Phenomena in Welds II, 1st ed., Springer, Berlin, Heidelberg, 2008, pp. 27-45.

14. Y. Tian, J.D. Robson, S. Riekehr, N. Kashaev, L. Wang, T. Lowe, and A. Karanika: Metall. Mater. Trans. A, 2016, vol. 47A, pp. 3533-44.
15. N. Bakir, A. Gumenyuk, and M. Rethmeier: Weld. World, 2016, vol. 60, pp. 1001-08.

16. L. Sweet, M.A. Easton, J.A. Taylor, J.F. Grandfield, C.J. Davidson, L. Lu, M.J. Couper, and D.H. Stjohn: Metall. Mater. Trans. A, 2013, vol. 44A, pp. 5396-407.

17. A.K. Dahle, T. Sumitomo, and S. Instone: Metall. Mater. Trans. A, 2003, vol. 34A, pp. 105-13.

18. J.M. Drezet, B. Mireux, G. Kurtuldu, O. Magdysyuk, and M. Drakopoulos: Metall. Mater. Trans. A, 2015, vol. 46A, pp. 4183-90.

19. M. Easton, L. Sweet, H. Wang, J. Grandfield, C.J. Davidson, D.H. Stjohn, and M.J. Couper: Metall. Mater. Trans. A, 2012, vol. $43 \mathrm{~A}$, pp. $3227-38$.

20. M. Sheikhi, F. Malek Ghaini, and H. Assadi: Acta Mater., 2015, vol. 82, pp. 491-502.

21. S. Tsirkas, P. Papanikos, and T. Kermanidis: J. Mater. Process. Technol., 2003, vol. 134, pp. 59-69.

22. Abaqus 6.14 Documentation, 1st ed., Dassault Systems, Providence, USA, 2013

23. T. Dickerson, Q. Shi, H.R. Shercliff: Proceedings of the Symposum on Frict. Stir Welding, USA, 2003, pp. 1-11.

24. R.H. Powell, C.Y. Ho, and P.E. Liley: Thermal Conductivity of Selected Metals, 1st ed., National Bureau of Standards, Washington, 1966, pp. 17-38.

25. B.G. Kıral, M. Tabanoğlu, and H.T. Serindağ: Math. Comput. Appl., 2013, vol. 18, pp. 122-31.

26. M. Riahi and H. Nazari: Int. J. Adv. Manuf. Technol., 2011, vol. 55 , pp. $143-52$.

27. V. Soundararajan, S. Zekovic, R. Kovacevic: Int. J. Mach. Tools Manuf., 2205, vol. 45, pp. 1577-87.

28. P.D. Desai: J. Phys. Chem. Ref. Data, 1986, vol. 15, pp. 967-83.

29. M. Li, J. Brooks, D. Atteridge, and W. Porter: Scripta Mater., 1997, vol. 36, pp. 1353-59.

30. A. De: Sci. Technol. Weld. Join., 2002, vol. 7, pp. 119-124.

31. T. Meek, Q. Han: Ultrasonic Processing of Materials (U.S. Department of Energy), 2006. https://www.osti.gov/scitech/servle ts/purl/85931. Accessed June 2006.

32. B. Banerjee and A. Bhawalkar: J. Mech. Mater. Struct., 2008, vol. 3, pp. 391-424.

33. R. Jain, S.K. Pal, and S.B. Singh: J. Manuf. Process., 2016, vol. 23, pp. $278-86$.

34. J. Schmitz, B. Hallstedt, J. Brillo, I. Egry, and M. Schick: J. Mater. Sci., 2012, vol. 47, pp. 3706-12.

35. J. Guo, J.Z. Zhu, and O.H. Lane: Int. Conf. Solidif. Process., 2007, pp. 549-53.

36. M.X. Xiong and J.Y.R. Liew: Thin-Walled Struct., 2016, vol. 98 , pp. 169-76.

37. M. De Strycker, L. Schueremans, W. Van Paepegem, and D. Debruyne: Opt. Lasers Eng., 2010, vol. 48, pp. 978-86.

38. W. Rohsenow, J. Hartnett, and Y. Cho: Handbook of Heat Transfer, 3rd ed., McGraw-Hill, New York, 1998.

39. R. Fan, J. Magargee, P. Hu, and J. Cao: Mater. Sci. Eng. A., 2013, vol. 574 , pp. $218-25$.

40. B.G. Zhang, T. Wang, X.H. Duan, G.Q. Chen, and J.C. Feng: Trans. Nonferrous Met. Soc. China, 2012, vol. 22, pp. 398-403.

41. V. Buchibabu, G.M. Reddy, and A. De: J. Mater. Process. Technol., 2017, vol. 24, pp. 86-92.

42. W. Kurz and D.J. Fisher: Fundamentals of Solidification, 3rd ed., Trans Tech Publications, Aedermannsdorf, 1992

43. S. Kou: JOM J. Miner. Metals Mater. Soc., 2003, vol. 55, pp. $37-42$.

44. J.I. Cho and C.W. Kim: Int. J. Metals, 2014, vol. 8, pp. 49-55.

45. M. Hasegawa and M. Watabe: J. Phys. Soc. Jpn., 1972, vol. 32, pp. 14-28. 